\title{
ASSESSING THE EFFICACY OF NITAZOXANIDE IN TREATMENT OF CRYPTOSPORIDIOSIS USING PCR EXAMINATION
}

\author{
By \\ MOHMMAD M. ATIA ${ }^{1}$, MOHIEDDIN M. ABDUL FATTAH ${ }^{1}$, \\ HANAN AMIN ABDEL RAHMAN ${ }^{2}$, FATEN A. MOHAMMED ${ }^{1 *}$ \\ AND ASMAA M. AL GHANDOUR ${ }^{1}$
}

Departments of Medical Parasitology' and Pediatrics ${ }^{2}$, Faculty of Medicine, Zagazig University, Sharkia Egypt ( ${ }^{*}$ Correspondence: fatenmr@yahoo.com)

\begin{abstract}
Cryptosporidiosis is a gastrointestinal disease of humans and other animals, caused by the genus Cryptosporidium spp. It causes persistent diarrhea and malnutrition and is associated with increased mortality. This study aimed to assess the efficacy of nitazoxanide (NTZ) on clearing the oocysts of $C$. parvum among infected children using both parasitological and PCR techniques. 120 children (1-12y) shedding Cryptosporidium oocysts in their stools were enrolled in the study. They were classified on the basis of the immune status into immunocompetent (ICT) and immunocompromised (ICZ) groups. Each group were subdivided into two groups one of them received NTZ, and the other received placebo. The efficacy of nitazoxanide was assessed clinically, parasitologically and by nested-PCR technique. At the end of $1^{\text {st }}$ week of treatment, $80 \%$ of ICT/ NTZ group and $40 \%$ of ICT/ placebo group were free by PCR and $83.3 \% \& 20 \%$ respectively were microscopically free. While at the end of $4^{\text {th }}$ week, $93.3 \%$ of ICT/ NTZ group and $43.3 \%$ of ICT/ placebo group were free by PCR and $96.7 \% \& 26.7 \%$ respectively were microscopically free. Among the ICZ group, diarrhea was resolved in most patients receiving NTZ within 21 to 28 days of treatment initiation While, it resolved in the ICT group receiving NTZ in most patients within 3 to 5 days of treatment initiation
\end{abstract}

Keywords: Nitazoxanide, Cryptosporidiosis, immunocompromised, PCR, Treatment

\section{Introduction}

Generally speaking, Cryptosporidiosis parvum is a zoonotic protozoan parasite infects intestinal epithelial cells of man and animals causing a major health problem (Abouel-Nour et al, 2016). They added that the reduction and elimination of shedding oocysts in response to the treatments might be attributable to a direct effect on parasite growth in intestines, sexual phases production and/or the formation of oocysts. The results were evaluated histopathological examination of ideum section of control mice (uninfected, untreated) displayed normal architecture of the villi C. parvum is a common cause of a mostly acute, self-limited, watery diarrhea in immunocompetent individuals (Gargala et al, 2000). In (HIV and non-HIV) immunodeficient subjects, cryptosporidiosis may lead to life-threatening chronic diarrhea and, because of the incidence of AIDS, it is a public health concern in many developing countries where AIDS is endemic (Griffiths, 1998).

Although stool microscopy was useful for identification of $C$. parvum infection, this tool is relatively insensitive when small numbers of oocysts are excreted or the period of oocyst shedding is short. Therefore, many infections may escape microscopic detection. Also El-Shazly et al. (2002) and Helmy et al. (2004) mentioned that detection of Cryptosporidium infection in stool by permanent stains showed lowest sensitivity and accuracy when compared to PCR. Hence improved methods for detection of Cryptosporidium oocysts in environmental and clinical samples are urgently needed to improve detection of cryptosporidiosis.

The TaqMan probes were specific for the genus Cryptosporidium, but could not hybridize exclusively with human-infectious $C$. parvum species and genotypes. DNA extraction was achieved with the diarrhea samples. This result indicates that $C$. parvum DNA extracted using the commercial kits is feasible on diarrheic feces, with large numbers of 
oocysts and small concentrations of PCR inhibitor. Yu et al. (2009) compared the sensitivity of 7 PCR primer sets for detection of Cryptosporidium parvum. Each target gene was amplified by PCR or nested PCR with serially diluted DNA extracted from purified $C$. parvum oocysts. They defined the COWP-nest primer for nested PCR as the most sensitive one in detecting Cryptosporidium gene.

Of the chemotherapeutic and immunotherapeutic agents tested in recent years, few have shown anti-cryptosporidium activity (Tzipori, 1998). None of the potential treatments for cryptosporidiosis has been shown to be effective in randomized controlled trials (Amadi et al, 2002; Abubakar et al, 2012). Infectious relapses are often observed after anti-cryptosporidial therapy, both in animal models and in clinical studies, primarily because parasites persist in the biliary tract, which is not reached by active agents, such as paromomycin, that are not absorbed from the digestive tract (Bissuel et al, 1994). Nitazoxanide yields a very reactive metabolite; tizoxanide (TIZ), and have a nitrogroup, which could undergo one electron reduction and recycling like metronidazole to yield significant amounts of superoxide radical anion, and hence become toxic to the anaerobic protozoa; suggesting that the nitro-group is essential for anti-protozoal activity (Adagu et al, 2002). This underlines the potential interest in agents such as nitazoxanide, which has already been shown to be active in vitro and to be readily absorbed from the gut. In humans, nitazoxanide is metabolized in vivo into tizoxanide and tizoxanide glucuronide, and these are the only metabolites detected in blood samples (Stockis et al, 1996).

\section{Subjects, Materials and Methods}

Study type: Prospective, randomized, double-blinded, controlled and experimental trial. Fecal samples of 370 children (1-12y) with acute or chronic watery, attending the Oncology and Nutrition units, of the Pediatrics' Department of Zagazig University Hospitals were screened to identify cryptosporidium oocysts and enroll 120 positive cryptosporidial cases in the study after parents' consent. These patients were classified on the basis of immune status into immune compromised (ICZ) (60 patients); under immune suppressive chemotherapy. The other 60 patients were considered as immune competent group (ICT). These two groups were subdivided into two groups (each group composed of 30 cases):

- ICT/ NTZ G: 30 cases received nitazoxanide suspension (age-balanced doses) twice daily for 3-4 days.

- ICT/ placebo G: 30 cases received placebo (honey-mixed aqueous solution) twice daily for 3-4 days.

- ICZ/ NTZ G: 30 cases received nitazoxanide suspension (age-balanced doses) twice daily for 7-28 days.

- ICZ/ placebo G: 30 cases received placebo (honey-mixed aqueous solution) twice daily for 7-28 days.

After macroscopic examination of all stool samples, they were preserved in sodium acetate acetic-acid formalin (SAF) stock solution. Formalin-ethyl acetate sedimentation technique was used for the detection of coccidian oocysts. The deposit was subjected to direct smear examination and Lugol's iodine as a temporary stain for detection of protozoal cysts. The smears were fixed in methyl alcohol to be subjected for permanent staining technique using Safranin-Trichrome stain. The period of each individual experiment continued for 4 weeks for follow-up.

The efficacy was assessed according to:

Clinical response (primary end point) from the time of initiation of treatment to the passage of the last unformed stool was recorded. It was at the days 7, 14, 21, \&28 and was either: "well" or continuing illness"

Parasitological response (secondary end point): It was assessed by examination of two stool samples of cases with persistent watery diarrhea for the presence of $C$. parvum oocysts by microscopic examination of SAFRANIN-TRICHROME stained smears 
after formol-ether concentration and by nested PCR technique. Samples were collected at the days $7 \& 8 ; 14 \& 15 ; 21 \& 22$ and $28 \& 29$ after treatment initiation. Parasitological response was recorded as either eradication or persistence.

Stool examination: Each stool sample was collected in a clean, dry, labeled, widemouth plastic cup (Fleck and Moody, 1988) and subjected to: Macroscopic examination: Including its consistency, presence of blood or mucus, color and odor.

Each stool sample was divided into 2 parts; first part was preserved in SAF stock solution (Junod, 1972) (1:3 parts) for microscopic examination, the second part was preserved and stored for molecular examination (0.2 $\mathrm{g}$ aliquot of each stool specimen was removed by taking cores of the stool sample with a cut-off $1 \mathrm{ml}$ syringe, where $0.2 \mathrm{ml}$ is $\approx 0.2 \mathrm{~g}$ (Nechvatal et al. 2008). Each $0.2 \mathrm{~g}$ core of feces was preserved at $-20^{\circ} \mathrm{C}$ within seven days, sealed in a sterile $50 \mathrm{ml}$ polypropylene tube and placed in $4^{\circ} \mathrm{C}$ refrigerator storage for 24 hours and then transferred to $80^{\circ} \mathrm{C}$ before conscription.

Microscopic examination: In order to detect even low burden of Cryptosporidium oocyst, two different procedures were done; formol-etheyl acetate concentration technique. (Jokipii et al. 1983 and reviewed by Chessbrough 2000) and permanent-stained smears by safranin-trichrome stain (Ponce de Leon et al. 1999).

Molecular Diagnosis (Pedraza-Díaz et al, 2001) nested PCR of the COWP gene included two consecutive PCR reactions. The first reaction amplified the $769 \mathrm{bp}$ fragment by using pair of primer setsBCOWPF-19: 5'-ACC GCT TCT CAA CAA CCA TCT TGT CCT C-3'; and BCOWPR-19: 5'-CGC ACC TGT TCC CAC TCA ATG TAA ACC C-3'. The second reaction contained two nested primers internal to the first primer pair and delimits a 311 bp fragment. These were Cowpnest-F1-15: 5'- TGT GTT CAA TCA GAC ACA C-3'and Cowpnest-R2-15 5'-
TCT GTA TAT CCT GGT GGG C3' The larger fragment produced by the first reaction was used as a template for the second reaction. Primers were synthesized with DNA synthesizer (OLIGOS, Fenland). It used for nested-PCR (Yu et al, 2009) PCR master mix was Maxime PCR PreMix Kit (i-Taq; for $20 \mu 1$ reaction) (Intron Biotechnology, Inc.). which is a ready-to-use mixture of $\mathrm{i}-\mathrm{Taq}^{\mathrm{TM}}$ DNA Polymerase $(5 \mathrm{U} / \mu \mathrm{l}), \mathrm{dNTPs}$, Reaction Buffer (10 X) and Gel Loading buffer.

Aamplification in each reaction was done by adding $2 \mu \mathrm{l}$ of template DNA and $2 \mu \mathrm{l}$ for each primer into Maxime PCR PreMix tubes and $14 \mu$ Distilled water was added into the tubes to reach a total volume of $20 \mu$ into Maxime PCR PreMix tubes.

The reaction was carried in with initial denaturation at $94^{\circ} \mathrm{C}$ for $5 \mathrm{~min}$, followed by 30 cycles of amplification of denaturation at $94^{\circ} \mathrm{C}$ for $50 \mathrm{sec}$, Annealing at $55^{\circ} \mathrm{C}$ for 30 $\mathrm{sec}$ and Extension at $72^{\circ} \mathrm{C}$ for $50 \mathrm{sec}$. Final extension was performed at $72^{\circ} \mathrm{C}$ for $10 \mathrm{~min}$. The second-round PCR was identical to the first-round PCR except for annealing at $60^{\circ} \mathrm{C}$ for $30 \mathrm{sec}$. (Yu et al, 2009).

The amplified PCR products were separated by electrophoresis on $2 \%$ agarose gel in TAE buffer and visualized under a transilluminator after staining with ethidium bromide. (Viljoen et al, 2005).

Statistical analysis: Data were calculated, tabulated and statistically analyzed using windows XP IBM SPSS Statistics. The collected data were entered, checked and analyzed using chi square $\left(\chi^{2}\right)$ (Knapp and Miller, 1992). The proportional clinical and parasitological response rates were compared by treatment group by $\mathrm{x}^{2}$ or Fisher's exact tests. $\mathrm{P}<0.05$ was considered significant, $\mathrm{P}<0.01$ was considered highly statistically significant, and $\mathrm{P} \geq 0.05$ was considered non-significant.

Ethical considerations: The study was approved by the Ethics Committee, Faculty of Medicine, Zagazig University, and children' parents signed an informed consent form. 


\section{Results}

48 of the 120 diarrheic patients passed $<5$ stools per day (they were 1-3 years old); from which $23(19.2 \%)$ were in ICT/ NTZ group and $5(4.2 \%)$ were in ICZ/ NTZ group. Also, 69 diarrheic patients passed 510 stools per day from which $7(5.8 \%)$ were in ICT/ NTZ group and $23(19.2 \%)$ were in ICZ/NTZ group. Mean duration of diarrhea at enrollment was $6.48 \pm 2.1$ days for patients in the ICT/ NTZ group and 20.8 \pm 11.1 days for patients in ICZ/ NTZ group with significant difference in comparison with placebo groups (Tab. 1).

Concerning the efficacy of nitazoxanide (NTZ) therapy at the $1^{\text {st }}$ week of treatment among the ICT/NTZ patients, highly significant statistical differences were observed in both the PCR parasitological response and the microscopic parasitological response $(\mathrm{M} / \mathrm{E})$ in relation to the placebo group $(\mathrm{P}<$ 0.001) Clinically, diarrhea was resolved in most patients receiving nitazoxanide within 3-5 days. Nitazoxanide treatment reduced the duration of diarrhea and increased stool consistency compared with a highly significant difference related to the placebo group ( $\mathrm{P}<0.001$ ), among ICZ/NTZ patients, non significant difference was observed in the PCR parasitological response, the microscopic parasitological response and clinical response among the patients in relation to placebo group (Tab. 2).

The efficacy of NTZ at the 4weeks gave highly significant differences in PCR parasitological response, the microscopic parasitolgical response $(\mathrm{M} / \mathrm{E})$ and clinical response among ICT/ NTZ patients and ICZ/NTZ patients in relation to placebo groups (Tab. 3). Diarrhea was resolved in most ICZ/NTZ patients within 21 to 28 days of treatment initiation.

At the end of $4^{\text {th }}$ week in ICT/NTZ group, non-significant difference was between clinical and the parasitological response (Safranin-Trichrome stain), while in ICT placebo group there was a significant difference. Among ICZ/NTZ \& ICZ /placebo patients, non-significant difference was between clinical and microscopic parasitological responses (Tab. 4). Among both NTZ \& placebo ICT patients and NTZ \& placebo ICZ patients non-significant difference was present between microscopic and PCR parasitological responses (Tab. 5).

Table 1: Clinical characteristics among the 120 Cryptosporidium infected children $(\mathrm{n}=30)$

\begin{tabular}{|c|c|c|c|c|c|}
\hline \multirow[t]{2}{*}{ Clinical Parameter } & \multicolumn{2}{|c|}{ ICT (I) } & \multicolumn{2}{|c|}{ ICZ(II) } & \multirow[t]{2}{*}{$P$.value } \\
\hline & NTZ & Placebo & NTZ & Placebo & \\
\hline Stool frequency $(/ 24 \mathrm{~h})$ & & & & & \\
\hline $3-4$ & $23(19.2 \%)$ & $20(16.7 \%)$ & $5(4.2 \%)$ & $0(0 \%)$ & $<0.001 * *$ \\
\hline $5-10$ & $7(5.8 \%)$ & $9(7.5 \%)$ & $23(19.2 \%)$ & $30(25 \%)$ & $<0.001 * *$ \\
\hline$>10$ & $0(0 \%)$ & $1(0.8 \%)$ & $2(1.7 \%)$ & $0(0 \%)$ & $<0.387$ \\
\hline Duration of diarrhea (days) & $6.48 \pm 2.1$ & $8.29 \pm 3.2$ & $20.8 \pm 11.1$ & $29.2 \pm 12.5$ & $<0.013$ \\
\hline
\end{tabular}

Table 2: Clinical and parasitological responses by microscopy \& PCR; by treatment groups; at $1^{\text {st }}$ week.

\begin{tabular}{|l|l|c|c|c|c|c|c|}
\hline \multirow{2}{*}{$1^{\text {st }}$ week study } & \multicolumn{2}{|c|}{$\mathrm{NTZ}$} & \multicolumn{2}{c|}{ Placebo } & \multirow{2}{*}{$\chi^{2}$} & \multirow{2}{*}{ P.value } \\
\cline { 3 - 8 } \multicolumn{1}{l|}{ ICT } & Nlinical response & 29 & 96 & $\mathrm{~N}=30$ & $\%$ & & \\
\cline { 2 - 8 } & $(\mathrm{M} / \mathrm{E})$ & 25 & 83.3 & 6 & 20.0 & 24.09 & $<0.001^{* *}$ \\
\cline { 2 - 8 } & $(\mathrm{PCR})$ & 24 & 80.0 & 12 & 40.0 & 10.0 & $<0.002^{* *}$ \\
\hline \multirow{3}{*}{ ICZ } & Clinical response & 3 & 10.0 & 0 & 0.0 & 3.16 & 0.076 \\
\cline { 2 - 8 } & $(\mathrm{M} / \mathrm{E})$ & 2 & 6.7 & 2 & 6.7 & 0.27 & 0.605 \\
\cline { 2 - 8 } & $(\mathrm{PCR})$ & 7 & 23.3 & 5 & 16.7 & 0.42 & 0.518 \\
\hline
\end{tabular}


Table 3: Clinical and parasitological responses by microscopy \& PCR; by NTZ \& Placebo groups; at whole (4 weeks) study.

\begin{tabular}{|c|c|c|c|c|c|c|c|}
\hline \multicolumn{2}{|c|}{4 weeks study } & \multicolumn{2}{|c|}{ NTZ $(\mathrm{N}=30)$} & \multicolumn{2}{|c|}{ Placebo $(\mathrm{N}=30)$} & \multirow[t]{2}{*}{$\chi^{2}$} & \multirow[t]{2}{*}{ p.value } \\
\hline & & No. & $\%$ & No & $\%$ & & \\
\hline \multirow[t]{3}{*}{ ICT } & Clinical response & 29 & 96.7 & 16 & 53.3 & 15.02 & $<0.001 * *$ \\
\hline & $(\mathrm{M} / \mathrm{E})$ & 29 & 96.7 & 8 & 26.7 & 31.09 & $<0.001 * *$ \\
\hline & (PCR) & 28 & 93.3 & 13 & 43.3 & 17.33 & $<0.001 * *$ \\
\hline \multirow[t]{3}{*}{$\mathrm{ICZ}$} & Clinical response & 19 & 63.3 & 3 & 10.0 & 18.37 & $<0.001 * *$ \\
\hline & $(\mathrm{M} / \mathrm{E})$ & 16 & 53.3 & 4 & 13.3 & 10.8 & $<0.001 * *$ \\
\hline & (PCR) & 16 & 53.3 & 7 & 23.3 & 5.71 & $<0.016^{*}$ \\
\hline
\end{tabular}

$*$ significant difference $(\mathrm{P}<0.05)$. $\quad$ ** highly significant difference $(\mathrm{P}<0.01)$.

Table 4: Patients' clinical response and parasitological response by Safranin-Trichrome (microscopy M/E) detected at end of $4^{\text {th }}$ week; in post-treatment stool samples by ICT\& ICZ groups

\begin{tabular}{|l|l|c|c|c|c|c|c|}
\hline \multirow{2}{*}{ Patients (N=30) } & \multicolumn{2}{|c|}{ Clinical response } & \multicolumn{2}{c|}{ Parasitological response } & \multirow{2}{*}{$\chi^{2}$} & \multirow{2}{*}{ p.value } \\
\cline { 2 - 8 } & No. & $\%$ & No & $\%$ & & \\
\hline \multirow{3}{*}{ ICT } & NTZ & 29 & 96.7 & 29 & 96.7 & 0.52 & 0.472 \\
\cline { 2 - 8 } & Placebo & 16 & 53.7 & 8 & 26.6 & 4.44 & 0.035 \\
\hline \multirow{2}{*}{ ICZ } & NTZ & 19 & 63.3 & 16 & 53.7 & 0.62 & 0.432 \\
\cline { 2 - 8 } & Placebo & 3 & 10.0 & 4 & 13.3 & 0.16 & 0.687 \\
\hline
\end{tabular}

Table 5: Patients' parasitological response by Safranin-Trichrome (microscopy) and nested-PCR; detected at end of $4^{\text {th }}$ week in post-treatment stool samples by ICT \& ICZ groups

\begin{tabular}{|l|l|c|c|c|c|c|c|}
\hline \multirow{2}{*}{$\begin{array}{l}\text { Patients } \\
(\mathrm{N}=30)\end{array}$} & \multicolumn{2}{|c|}{$(\mathrm{PCR})$} & \multicolumn{2}{|c|}{$(\mathrm{M} / \mathrm{E})$} & \multirow{2}{*}{$\chi^{2}$} & \multirow{2}{*}{ p.value } \\
\cline { 3 - 7 } & No. & $\%$ & No. & $\%$ & & \\
\hline \multirow{2}{*}{ ICT } & NTZ & 28 & 93.3 & 29 & 96.7 & 0.35 & 0.554 \\
\cline { 2 - 8 } & Placebo & 13 & 43.3 & 8 & 26.6 & 1.83 & 0.175 \\
\hline \multirow{2}{*}{ ICZ } & NTZ & 16 & 53.3 & 16 & 53.3 & 0.07 & 0.795 \\
\cline { 2 - 7 } & Placebo & 7 & 23.3 & 4 & 13.3 & 1.0 & 0.316 \\
\hline
\end{tabular}

\section{Discussion}

In the present study, all the infected cases were chosen from diarrheic patients. This agreed with McDonald et al. (2001) and Priest et al. (2003) who stated that C. parvum was an important cause of the diarrhea worldwide. Previously, Moss et al. (1998) and Priest et al. (1999) reported asymptomatic Cryptosporidium infected cases.

In the present study, fecal samples were examined by different methods. Cryptosporidium oocysts could not be identified in unstained wet mounts, but formol-ether concentration was the most sensitive sedimentation technique, which agreed with $\mathrm{McNabb}$ et al. (1985). Also, the oocysts were identified by formal-ether sedimentation (Casemore et al, 1985) stained by SafraninTrichrome stain after fixation with methanol, with homogenous orange-pink colored of varying degree of intensity against a blu- ish background. This agreed with Ponce de Leon et al. (1999).

Although the stool microscopy was useful for identification of C. parvum, but relatively insensitive with small numbers of oocysts or the period of its shedding and positive infections escaped microscopic detection. El-Shazly et al. (2002) and Helmy et al. (2004) found that detection of C. parvum in stool by permanent stains gave lowest sensitivity and accuracy compared to PCR. Yu et al. (2009) compared the sensitivity of seven PCR primer sets for detection of C. parvum, each target gene was amplified by PCR or nested PCR with serially diluted DNA extracted from purified oocysts. The target genes included $C$. parvum oocyst wall protein (COWP), small subunit ribosomal RNA (SSU rRNA), and random amplified polymorphic DNA.

The present study agreed with $\mathrm{Yu}$ et al. (2009), where the second-round amplifica- 
tion using $311 \mathrm{bp}$-primer of target gene showed that the nested primer set specific for the (COWP) gene proved to be the most sensitive one for C. parvum. The PCR detection limit with $\mathrm{Yu}$ et al. (2009) ranged from $10^{3}$ to $10^{4}$ oocysts, while the nested PCR was able to detect $10^{0}$ to $10^{2}$ oocysts as low as a single oocyst. They concluded that the most sensitive nested PCR target gene was COWP and the primers cowpnest-F1 and cowpnest-R2 detected as low as a single oocyst..

In immunocompetent hosts, the disease is more or less self-limiting, as in the present study; the mean duration of diarrhea at enrollment was $6.48 \pm 2.1$ days for patients in the nitazoxanide treatment immunocompetent group and $20.8 \pm 11.1$ days for patients in the NTZ treatment immunocompromised group, compared with $8.29 \pm 3.2$ days for the immunocompetent placebo group and $29.2 \pm 12.5$ days with significant difference; but in immunocompromised hosts, the disease could be chronic and debilitating this was in agreed with Pozio et al. (1997).

Amadi et al. (2001) defined clinical response on day seven as either well (no symptoms, no watery stools, no more than two soft stools/ 24 hours, or no symptoms and no unformed stools within past 48 hours) or continuing illness (not fulfilling definition of well). The parasitologic response was assessed by two stool samples on day seven and eight for oocyst by auramine phenol smear microscopy. Response was categorized as either eradication (no oocyst in either post-treatment sample) or persistence (oocyst in either or both posttreatment samples).

In the present study, at 7 days after therapy initiation; diarrhea resolved in ICT/NTZ group, with a highly significant difference to placebo group. Diarrhea was resolved in most patients receiving NTZ within 3 to 5 days of treatment. Diarrhea was resolved in the present study in most ICZ patients receiving NTZ within 21 to 28 days of treatment. NTZ reduced diarrhea duration and increased stool consistency without significant difference in relation to placebo.

Rossignol et al. (2001) in Benha Governorate evaluated the efficacy of NTZ in treating C. parvum diarrhea. They gave NTZ as $500 \mathrm{mg}$ doses twice daily for 3 days to adults and adolescents, in 200mg doses twice daily for 3 days to children aged 4-11 years, and $100 \mathrm{mg}$ doses twice daily for 3 days to children aged 1-3 years.

They agreed with the present study as they found 96/100 (96\%) patients passed 5-10 stools/ day, and 4/100 passed $>10$ stools/day and 39 patients had liquid stools, and 61 semisolid stools. Mean diarrhea duration was 13.22 days (range, 5-97 days) for patients in the NTZ treatment, compared to 12.76 days (range, 5-90 days); for placebo group. At enrollment, diarrhea had resolved (clinical response) in 39/49 (80\%) of patients on NTZ treatment group at 7 days post therapy, compared with $20 / 49(41 \%)$ in placebo group with a high significant difference. This diarrhea was resolved in most patients receiving NTZ within 3-4 days of treatment, also. NTZ reduced the duration of diarrhea and oocyst shedding with a high significant difference. C. parvum was eradicated (parasitological response) based on two post-treatment negative fecal examinations in 33/49 (67\%) of patients on NTZ vs. $11 / 50(22 \%)$ patients on a placebo with a highly significant difference (Rossignol et al, 2001).

The present study were perceived by Rossignol et al. (1998) and Amadi et al. (2002) for resolution of diarrhea, showing no evidence of effectiveness for NTZ compared to placebo in immunocompromised patients during $1^{\text {st }}$ week of treatment.. NTZ led to a significant parasitologic response compared with placebo among all children, but without significant for immunocompromised participants. Immunocompetent participants on NTZ had a significantly higher response of achieving parasitological clearance. Abdel Maboud et al. (2000) studied cryptosporidiosis on 1087 diarrheal patients of all age 
groups using the modified Ziehl-Neelsen stain (MZN) and Meriflour direct immunoflourescent technique (IFA), by divided cases into 3 groups; each group was treated with NTZ or co-trimoxazole, or placebo. The most effective drug was NTZ cured $39 / 49$ (79.6\%) diarrheal patients followed by co-trimoxazole gave cure of 20/48 (41.6\%) and Placebo cured 20/50 (40\%) of patients.

Practice guide-lines for the prevention and treatment of cryptosporidiosis were given (CDC 1995; Kaplan et al, 2002). The paucity of evidence for an effective intervention meant that most of these guidelines rely on the studies done on poor quality. Shalaby and Shalaby (2015) in Egyptian school children reported a significant relation between cryptosporidiosis and low socio-economic level in the rural area. They added that a significant relation was obtained between $C$. parvum infection and the presence of animal contact. For HIV-infected persons, highly active antiretroviral therapy (HAART) was the bastion of preventing and managing cryptosporidiosis. It led to complete resolution of clinical symptoms and oocysts (Grube et al, 1997, Maggi et al, 2000; Miao et al, 2000). This intervention was not available for the HIV patients who failed or were unable to access HAART in the developing countries.

No doubt, among these immunocompromised persons without the option of an effective treatment for the underlying disease, supportive management, including rehydration therapy, electrolyte replacement, and anti-motility agents would remain the only alternatives for the human-care until better and specific drugs emerge.

\section{Conclusion}

This study proved that the absence of substantiation for effective agents in executive of cryptosporidiosis. The nitazoxanide gave marked clearance of oocysts and useful with immunocompetent individuals.

Given the importance of the outcomes of infection in immunocompromised individuals, it is worth considering using NTZ while clinicians await further evidence for its effectiveness in the immunocompromised patients. Undoubtedly, the use of the fluid and the electrolyte replacement as well as the anti-motility agents might be the choice for the mass of immunocompromised patients.

The highly sensitive nested PCR method proved helpful for cryptosporidiosis detection in patients with a low number of oocysts and could be a valuable tool for detection of oocysts in environmental and clinical samples

\section{References}

Abdel Maboudm AI, Rossignol, JF, EI Kady, MS, Mostafa, MS, Kabil, SM, 2000: Cryptosporidiosis in Benha, study of some recent modalities in diagnosis and treatment. J. Egypt. Soc. Parasitol. 30, 3:717-25.

Abouel-Nour, MF, El-Shewehy, DM, Hamada, SF, Morsy, TA,2016: The efficacy of three medicinal plants; garlic, ginger and mirazid and a chemical drug metronidazole against Cryptosporidium parvum: II-Histological changes. J. Egypt. Soc. Parasitol. 46, 1:185-200;

Abubakar, II, Aliyu, SH, Arumugam, C, Hunter, PR, Usman, NK, 2012: Prevention and treatment of cryptosporidiosis in immunocompromised patients: The Cochrane Collaboration by. John Wiley \& Sons, Ltd.http://www. Theco chranelibrary.com.

Adagu, IS, Nolder, D, Warhurst, DC, Rossignol, JF, 2002: In vitro activity of nitazoxanide and related compounds against isolates of Giardia intestinalis, Entameoba histolytica and Trichomonas vaginalis. J. Antimicro. Chemo. 49:103-11.

Amadi, B, Kelly, P, Mwiya, M, Mulwazi, E, Sianongo, S, 2001: Intestinal and systemic infection, HIV, and mortality in Zambian children with persistent diarrhea and malnutrition. J. Pediatr. Gastroenterol. Nutr. 32:550-4.

Amadi, B, Mwiya, M, Musuku, J, Watuka, A, Sianongo, S, et al, 2002: Effect of nitazoxanide on morbidity and mortality in Zambian children with cryptosporidiosis: a randomised controlled trial. Lancet; http: //image.thelancet.com/extras/ 01 art10193web. pdf.

Bissuel, F, Cotte, L, Rabodonirina, M, Rougier, P, Piens, MA, et al, 1994: Paromomycin: an effective treatment for cryptosporidial diar- 
rhea in patients with AIDS. Clin. Infect. Dis.18: 447-9.

Casemore, DP, Armstrong, M, Sands, RL, 1985: Laboratory diagnosis of cryptosporidiosis. J. Clin. Pathol. 38:1337-41. .

CDC, 1995: Cryptosporidium in water: CDC Guidelines on How to Protect Yourself. AIDS Treat News 227:7-8.

Chessbrough, M, 2000: District Laboratory Practice in Tropical Countries, (Part I). Tropical Health Technology, Cambridge University Press.

El-Shazly, AM, Gabr, A, Mahmoud, MSE, Abdel-Aziz, SS, Saleh, WA, 2002: The use of Ziehl-Neelsen stain, enzyme linked immunosorbent assay and nested polymerase chain reaction in diagnosis of cryptosporidiosis immunocompetent and immunocompromised patients. J. Egypt. Soc. Parasitol. 32, 1:155-66.

Fleck, S, Moody, A, 1988: Diagnostic Techniques in Medical Parasitology. $11^{\text {th }}$ ed., ELBS, Butterworth, Henemann, the United Kingdom.

Gargala, G, Delaunay, A, Li, X, Brasseur, P, Favennec, L, et al, 2000: Efficacy of nitazoxanide, tizoxanide and tizoxanide glucuronide against Cryptosporidium parvum development in sporozoite-infected HCT-8 enterocytic cells. J.. Antimicrob. Chemother. 46:57-60.

Griffiths, JK, 1998: Human cryptosporidiosis; epidemiology, transmission, clinical disease, treatment and diagnosis: Opportunistic protozoa in humans. Adv. Parasitol. 37:85-9.

Grube, H, Ramratnam, B, Ley, C, Flanigan TP, 1997: Resolution of AIDS associated cryptosporidiosis after treatment with indinavir. Am. J. Gastroenterol. 92, 4:726-9.

Helmy, MMF, Rashed, LA, El-Garhy, MF, 2004: Molecular characterization of Cryptosporidium parvum isolates obtained from humans. J. Egypt. Soc. Parasitol. 34, 2:447-58.

Jokipii, LS, Phjola, S, Hokipii, MM, 1983: Cryptosporidium: a frequent finding in patients with gastrointestinal symptoms. Lancet 1:35861.

Junod, C, 1972: Technique coprologique nouvelle essentiellement destinee ala concentration des trophozoites d'amibes. Bull. Soc. Pathol. Exot. Filial. 65:390-8.

Kaplan, JE, Masur, H, Holmes, KK, 2002: Guidelines for preventing opportunistic infections among HIV-infected persons: Recommendations of the U.S. Public Health Service and the
Infectious Diseases Society of America. MMWR Recomm Rep 51, 8:1-52.

Knapp, RG, Miller, MC, 1992: Clinical Epidemiology and Biostatistics. Baltimore, Williams and Wilkins.

Maggi, P, Larocca, AM, Quarto, M, Serio, G, Brandonisio, O, et al, 2000: Effect of antiretroviral therapy on cryptosporidiosis and microsporidiosis in patients infected with human immunodeficiency virus type 1. Eur. J. Clin. Microbiol. Infect. Dis. 19, 3:213-7.

McDonald, AC, MacKenzie, WR, Addiss, DG, Gradus, MS, Linke, G, et al, 2001: Cryptosporidium parvum-specific antibody response among children residing in Milwaukee during the 1993 waterborne outbreak. J. Infect. Dis. 183:1373-9.

McNabb, SJ, Hensel, DM, Welch, DF, Makee, GL, Istree, GR, 1985: Comparison of sedimentation and floatation techniques for identification of Cryptosporidium sp. oocyst in large outbreak of human diarrhea. J. Clin. Microbiol. 22:587-9.

Moss, DM, Bennett, SN, Arrowood, MJ, Hurd, MR, Lammie, PJ, et al, 1998: Enzyme-linked immune-electrotransfer blot analysis of a cryptosporidiosis outbreak on a United States Coast Guard cutter. Am. J. Trop. Med. Hyg. 58: 110-8.

Nechvatal, JM, Ram, JL, Basson, MD, Namprachan, P, Niec, SR, et al, 2008: Fecal collection, ambient preservation, and DNA extraction for PCR amplification of bacterial and human markers from human feces. J. Microbiol. Meth. 72:124-32.

Pedraza-Díaz, S, Amar, C, Nichols, GL, McLauchlin, J, 2001: Nested polymerase chain reaction for amplification of the Cryptosporidium oocyst wall protein gene. Emerg. Infect. Dis. 7, 1:49-56.

Ponce de Leon, P, Flaherty, P, Zdero, M, 1999: A new Safranin-Trichrome stain for the detection of Cryptosporidium parvum, Cyclospora cayetanensis, species of microsporidia and Isospora belli in faecal material. Rev. Latin. Am. Microbiol. 41:211-4.

Pozio, E, Rezza, G, Boschini, A, Pezzotti, P, Tamburrini, A, et al, 1997: Clinical cryptosporidiosis and human immunodeficiency virus (HIV)-induced immunosuppression: findings from a longitudinal study of HIV-positive and HIV-negative former injection drug users. J. Infect. Dis. 176:969-75. 
Priest, JW, Kwon, JP, Moss, DM, Roberts, JM, Arrowood, MJ, et al, 1999: Detection of enzyme immunoassay of serum immunoglobulin $\mathrm{G}$ antibodies that recognize specific Cryptosporidium parvum antigens. J. Clin. Microbiol. 37: 1385-92.

Priest, JW, Mehlert, A, Arrowood, MJ, Riggs, MW, Ferguson, MAJ, 2003: Characterization of a low molecular weight glycolipid antigen from Cryptosporidium parvum. J. Biol. Chem. 278:5212-22.

Rossignol, JF, Ayoub, A, Ayers, MS, 2001: Treatment of diarrhea caused by Cryptosporidium parvum: a prospective randomized, doubleblind, placebo-controlled study of Nitazoxanide. J. Infect. Dis. 184:103-6.

Rossignol, JF, Hidalgo, H, Feregrino, M, 1998: A double-blind placebo controlled study of nitazoxanide in the treatment of cryptosporidial diarrhea in AIDS patients in Mexico. Trans. R. Soc. Trop. Med. Hyg. 92:663-6.
Shalaby, NM, Shalaby, NM, 2015: Cryptosporidium parvum infection among Egyptian school children. J. Egypt. Soc. Parasitol. 45, 1:125-31.

Stockis, A, Lins, R, Deroubaix, X, Jeanbaptiste, B, Calderon, $\mathrm{P}$, et al, 1996: Pharmacokinetics of nitazoxanide after single oral dose administration in 6 healthy volunteers. Int. J. Clin. Pharmacol. Therap. 34:349-51.

Tzipori, S, 1998: Cryptosporidiosis: laboratory investigations and chemotherapy. Adv. Parasitol. 5:36-9.

Viljoen, GJ, Nel, LH, Crowther, JR, 2005: Molecular Diagnostic PCR Handbook. Dordrecht, The Netherlands, Springer.

Yu, JR, Lee, SU, Park, WY, 2009: Comparative sensitivity of PCR primer sets for detection of Cryptosporidium parvum. Korean J. Parasitol. 47, 3:293-7.

\section{Explanation of figures}

Fig. 1: Cryptosporidium oocysts, stained by Safranin-Trichrome stain, X 1000.

Fig, 2: $769 \mathrm{bp}+\mathrm{ve}$ bands in $1^{\text {st }}$ step of nested-PCR.

Fig. 3: $311 \mathrm{bp}+\mathrm{ve}$ bands in $2^{\text {nd }}$ step of nested-PCR. 


\section{F. 1}

F. 2

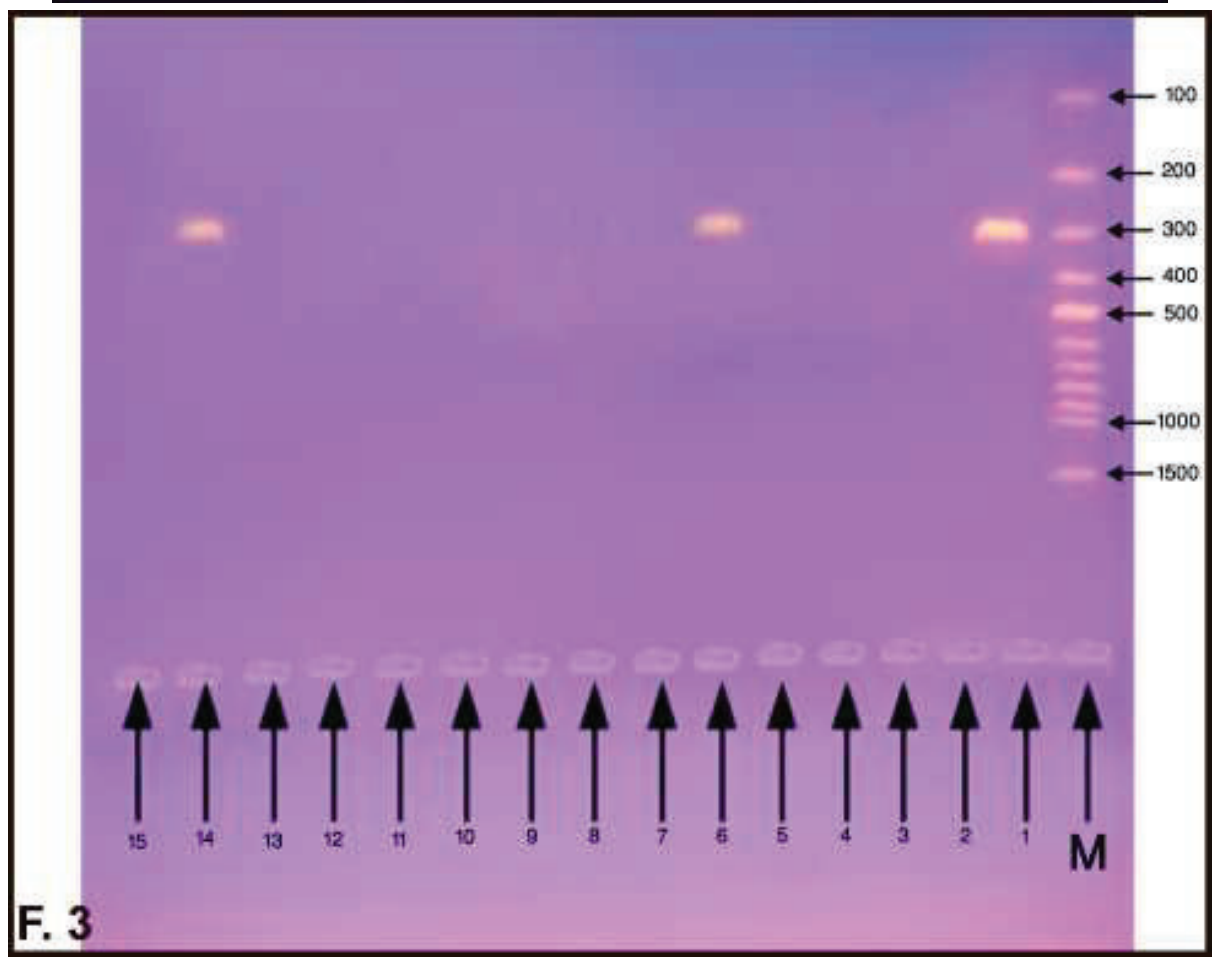

